\title{
Le Thesaurus de l'Image Médicale de Strasbourg 010
}

A. Wackenheim

Institut de Radiologie, Faculté de Médecine, 11, rue Humann, F-67000 Strasbourg

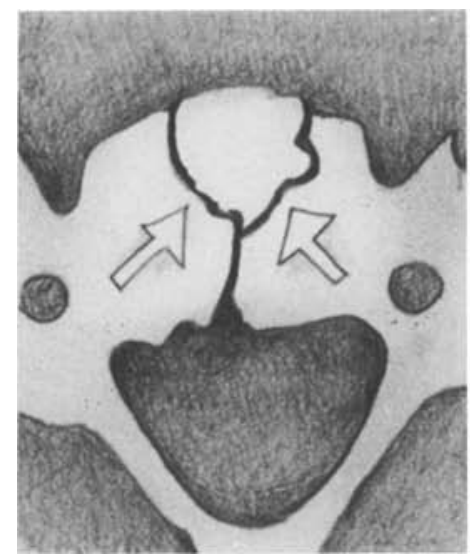

C132

Veines vertébrales corporéales cervicales en " $\mathrm{Y}$ " (N) (TDM)

"Y" shaped cervical corporeal veins $(\mathrm{N})(\mathrm{CT})$

"Y" Form der Wirbelkörpervenen der HWS (N) (CT)

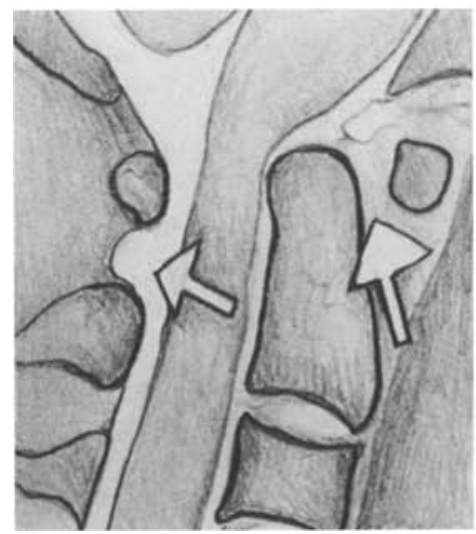

\section{C106}

Dislocation C1-C2 avec compression médullaire et dilatation postêrieure de la citerne au même niveau (P) (IRM - T2)

C1-C2 dislocation with spinal compression and dilatation of the posterior arachnoidal space between C1-C2 (P) (MRI - T2)

C1-C2 Dislokation mit spinaler Kompression und Erweiterung des dorsalen Arachnoidalraumes von $\mathrm{C} 1-\mathrm{C} 2(\mathrm{P})(\mathrm{MRI}-\mathrm{T} 2)$

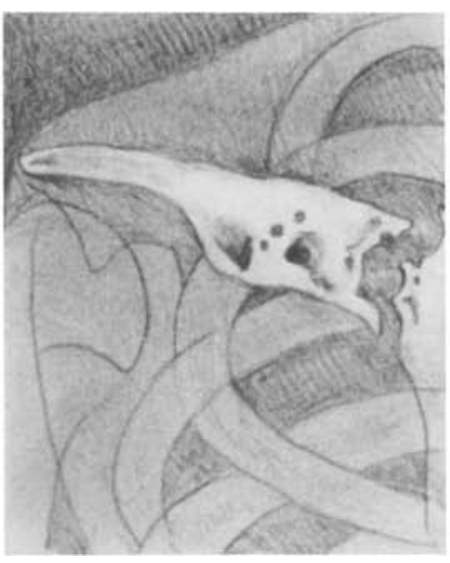

\section{C144}

Ostéite sterno-claviculaire aseptique (S) (RX) Aseptic sternoclavicular osteitis (S) (RX) Aseptische sternoclaviculäre Osteitis (S) (Rö)

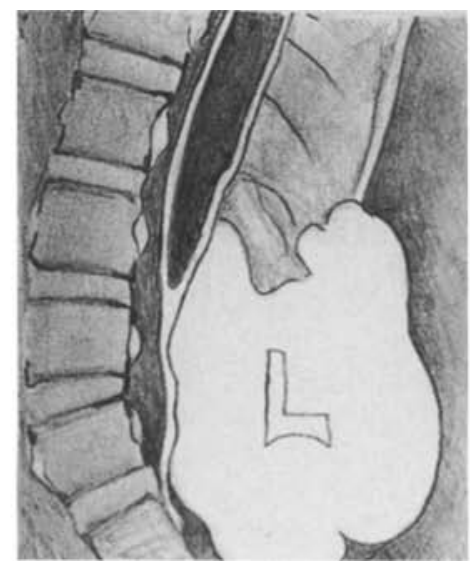

\section{B189}

Malformation de Chiari avec rachischisis lombaire, moelle fixée à $\mathrm{S} 1$, cavité syringomyélique et méningocèle contenant un lipome (P) (IRM - T1)

Chiari malformation with lumbar rachischisis, tethered cord at the level of S1, lumbar Syrinx and meningocele with lipoma (P) (MRI- T1)

Chiari Fehlbildung mit Rachischisis der Lendenwirbelsäule, fixierte Medulla bei S1, syringomyelische Zyste und Meningocele mit Lipom (P) (MRI - T1)

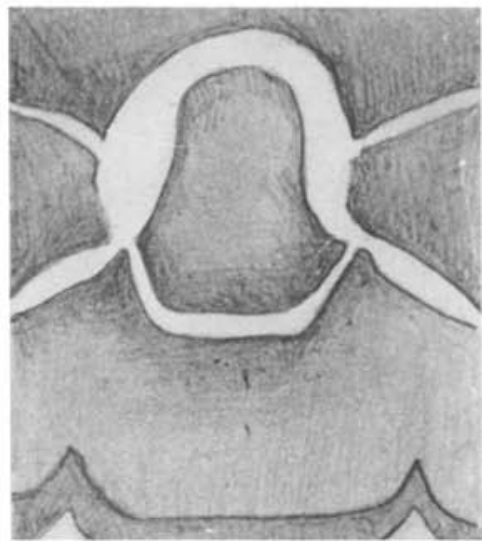

\section{C133}

Persistance du disque C1-C2 (P) (RX)

Persistent C1-C2 disk (P) (RX)

Persistenz der Zwischenwirbelscheibe C1-C2 (P) (Rö)

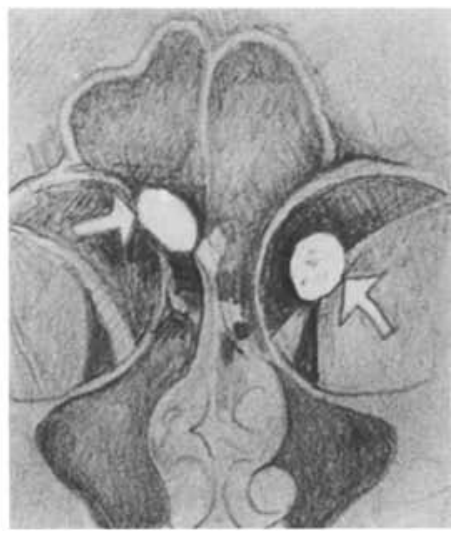

\section{C104}

Ostéomes de l'étage antérieur de la base du crâne (S) (RX)

Osteomas of the anterior groove of the skull base (S) (RX)

Osteome der vorderen Schädelgrube der Schädelbasis (S) (Rö) 